\title{
The Outcome of Adolescent-Onset Anorexia Nervosa: A Study of 144. Cases
}

\author{
Solenn Kermarrec1 ${ }^{*}$, Bernard Kabuth ${ }^{2}$, Anne-Christine Rat ${ }^{3,4}$, Michel Vidailhet ${ }^{5}$, \\ Colette Vidailhet ${ }^{2}$ \\ ${ }^{1}$ Pôle Hospital Universitaire de Psychiatrie de l'Enfant et l'adolescent, Rennes, France \\ ${ }^{2}$ Service de Psychiatrie de l'Enfant et de l'Adolescent, CHU Nancy, Nancy, France \\ ${ }^{3}$ EA 3444, Faculté de Médecine, Université Henri Poincaré Nancy I, Nancy, France \\ ${ }^{4}$ Centre d'Epidémiologie Clinique, INSERM CIE6, Service d’Epidémiologie et Evaluation Cliniques, Hôpital Marin, \\ CHU Nancy, Nancy, France \\ ${ }^{5}$ Service de Pédiatrie 3 et Génétique, CHU Nancy, Nancy, France \\ Email: ${ }^{\text {s.kermarrec@ch-guillaumeregnier.fr }}$
}

Received 25 May 2014; revised 11 July 2014; accepted 26 July 2014

Copyright @ 2014 by authors and Scientific Research Publishing Inc. This work is licensed under the Creative Commons Attribution International License (CC BY). http://creativecommons.org/licenses/by/4.0/

(c) (i) Open Access

\begin{abstract}
Objectives: To evaluate the long-term outcome of adolescents with anorexia nervosa and attempt to define prognostic factors for outcome. Methods: Transversal, descriptive epidemiological study with a strict methodology: minimum interval of 4 years since first admission, evaluation using clearly defined diagnostic criteria (EAT-40 self-evaluation, HSCL, global patient-driven self-evaluation and hetero evaluation: clinical interview and LECE). The 198 subjects are former adolescent anorexics treated at the Hôpital d'Enfants (Children's Hospital) in Nancy (France). Results: Clinical evaluation of the 144 subjects traced showed positive outcome for $68.1 \%$, intermediate outcome for $23.2 \%$ and poor outcome for $\mathbf{8 . 7 \%} 5$ factors for a good prognosis were found (middle socioeconomic class of parents, no prior treatment, hospitalization $>1$ month, follow-up $<12$ months, no re-admission to hospital). Discussion: This study, which is one of the largest studies on the outcome of adolescent-onset anorexia nervosa in France, shows the value of integrated treatment within a children's hospital.
\end{abstract}

\section{Keywords}

Anorexia Nervosa, Adolescent, Epidemiology, Prognosis, Outcome

\footnotetext{
${ }^{*}$ Corresponding author.
} 


\section{Introduction}

Anorexia nervosa is a complex, serious disorder whose course is often slow and difficult to predict. The longterm outcome is uncertain and anorexia remains a potentially fatal condition.

In a meta-analysis of 119 outcome series composed of 3099 patients in which STEINHAUSEN compared a group of patients with adolescent onset $(n=784)$ and a group with a much wider age range at onset of illness (2315), there was a significantly lower mortality rate in the younger patient group [1]. The recovery, improvement, and chronicity rates were also more favourable in this group.

He found two main factors mitigating the problematic outcome of anorexia nervosa: duration of follow-up and age at onset of the disorder. In contrast to the strong effect of the increasing crude mortality rate, the global outcome in the surviving patients clearly improves with increasing duration of follow-up. While younger age at onset is associated with better outcome, the duration of follow-up is a more influential factor.

However, this type of study is associated with methodological problems related to the study population itself, the inclusion criteria, evaluation instruments and length of monitoring. In the absence of an established consensus, it is difficult to compare results of the different studies. In 1996, HSU therefore defined a set of methodological criteria that have since been accepted and recognized by a number of authors [2]:

1) Explicitly stated diagnostic criteria so that atypical cases are excluded;

2) More than 25 subjects in the study;

3) Minimum follow-up of 4 years from onset of illness;

4) Less than $20 \%$ rate of failure in tracing patients;

5) The use of direct interview at follow-up for more than half of the patients;

6) The use of multiple well-defined outcome measures.

To date, a few prospective studies of adolescent patients with eating-disorders, with a follow-up period of at least 4 years, have been published. In this study of 49 adolescents, they find a good outcome in $47 \%$, an intermediate outcome in $43 \%$ and a poor outcome in $10 \%$ [3]. They explain these particularly good results by the young age of the patients and their relatively mild disturbances.

In 1991, Jeammet evaluated the outcome of 129 adolescents with anorexia nervosa [4]. The follow-up period ranged from 4 to 20 years (11.7 \pm 3 years). Of the 76 subjects for which complete outcome data were available, JEAMMET found that the overall outcome was good for $47 \%$ of patients, intermediate for $38 \%$ and poor for $15 \%$.

In our study, our primary objective was to evaluate the outcome of former anorexics treated at the Children's Hospital within the Centre Hospitalier Universitaire (CHU) in Nancy since the paediatric and adolescent psychiatric unit opened and then to compare our adolescent outcome results to those reported in the literature. Our secondary objective was to define potential prognostic factors for the outcome of these former patients.

\section{Methods}

This is a transversal descriptive epidemiological study assessing the long-term outcome of adolescent-onset anorexia nervosa and retrospectively assessing prognostic factors for patient outcome.

\subsection{Population}

The population consists of anorexic adolescents treated at the Nancy CHU Children's Hospital since the first case of teenage anorexia nervosa was admitted to the unit for psychiatric care until 4 years before the study. The data from our study was statistically analyzed allowed a minimum four year interval since onset of the disorder as recommended by HSU.

The researcher and the clinicians checked the following inclusion and exclusion criteria in each medical file:

Inclusion criteria

- Diagnosis of anorexia nervosa as per ICD-10 criteria, controlled and checked by an experienced clinician [5].

- Age more than 11 at the time of diagnosis so that no pre-pubertal forms of the disease are included.

- Anorexia nervosa diagnosed more then 4 years before the study.

- Outpatient or inpatient medical care, or combination of both.

Exclusion criteria

- Organic disease with appetite disorders and/or weight loss (for example, Crohn's Disease, hyperthyroidism or brain tumour). 
- Eating disorder related to or masking a psychiatric illness such as bipolar disorder, schizophrenia, temporary refusal to eat associated with hysterical behaviour, deglutition phobia and depression.

\subsection{Instrumentation}

Our assessment criteria correspond to the different long-term outcomes of teenagers having suffered from anorexia nervosa evaluated using a variety of diagnostic systems:

- Patient-driven self-evaluation questionnaires:

A general questionnaire and two validated self-evaluation scales, the Eating Attitudes Test (EAT-40) and the Hopkins Symptom Check List (HSCL) were completed by the subjects [6] [7].

The EAT-40, a validated and recognized questionnaire used to evaluate eating disorders, consists of 40 questions, each with answers on a six-point scale [7].

The HSCL general mental health assessment scale consists of 58 items with answers on a four-point ordered scale [6].

- A heteroevaluation scale filled in by the examiner:

The LECE, Liste d'Evaluation Clinique par l'Examinateur (the examiner's clinical assessment chart) devised by JEAMMET which allows the outcome of anorexia nervosa to be described using 10 items (eating habits, weight, menstruation, mental state, insight capacity, sexual relations, friendships, social contacts outside the family, occupation (profession or studies) and addictive behaviours).

During a direct or telephone clinical interview, the examiner adds up the number of items. JEAMMET used this chart to divide the overall outcome of subjects into 3 categories: "Good", "Intermediate", and "Poor".

\subsection{Data Collection}

During 4 months, we contacted each subject included in the study by telephone to ensure that the address details we had on file were still correct, then we sent an envelope containing a letter which explained the nature of the study and proposed a clinical interview, the two self-questionnaires to be completed and a stamped envelope addressed to our department.

Contacting our study population was at times difficult, particularly in view of the time elapsed since treatment. These patients were teenagers when they were first admitted to the unit, and were therefore highly likely to have changed address since that time. In addition, some former patients did not want to be reminded of painful memories by participating in our study.

Evaluation of individual outcomes was most complete when a clinical interview was possible. This semistructured, individual interview lasted approximately an hour and a half and took place in the paediatric and adolescent psychiatric clinic at the Children's Hospital. During this interview, the patient's general health status in terms of eating habits, social coping, relationships and mental health was explored. The ten items on the LECE clinical assessment scale were then completed to evaluate the overall outcome of the patient.

If it was still impossible to contact the subject, and having ensured that he/she had not died in the interim, the subject was considered to be lost to follow-up.

After analysis of the studies on anorexia outcome reported in the literature, we collected the following data: age at onset of illness, duration of symptoms, duration of inpatient symptoms, weight loss, hyperactivity, dieting, vomiting, bulimia and purgative abuse, premorbid developmental or clinical abnormalities, parent-child relationship and socioeconomic status.

\subsection{Statistical Analysis}

The data were statistically analyzed using SAS 8.2 software [8].

The relationships between the outcomes as assessed using the EAT-40, HSCL and LECE systems and the demographic data and initial clinical characteristics were analyzed using variance analysis or Chi2 tests. Pearson's coefficient of correlation was used to measure the linear relationship between two variables. The means were compared using a Student $T$ test, and distribution frequency using a Chi2 test (population less than 5) or Fisher's exact test (population more than than 5).

The scores obtained on the different outcome diagnostic systems were compared with the variables studied using non parametric tests in view of the small populations in certain groups. The Wilcoxon test was used to compare the means of a qualitative variable with two possible answers. Qualitative variables with more than two 
possible answers were compared using the Kruskall-Wallis test. Statistically significant variables $(\mathrm{p}<0.05)$ that were considered liable to be prognostic factors for the outcome of anorexia nervosa were selected.

Multivariate analysis with logistic regression makes it possible to express the link between dependent and independent variables. During evaluation in our study, we attempted to explain outcome as a function of the preexisting data collected (independent variables). To allow the variables selected to be included in the analysis, the independent quantitative variables were recoded in binary mode taking their median as the limit. The median is a central position parameter giving the value which divides a distribution into two equal populations. We also used the median of the scores our sample obtained on the HSCL questionnaire, to model the results observed within our population. The median score on the HSCL is 36. We used the classification system defined by JEAMMET and described above to modelize LECE scores.

Logistic regression analysis was used to study the prognostic factors, with outcome as defined by the LECE, EAT-40 and HSCL as dependent variables, and the demographic and clinical variables drawn from the medical notes taken at the time of first admission together with the intermediate treatment variables (medical and psychological and any subsequent hospitalizations) as independent variables.

The odds ratio (OR) and confidence intervals were calculated. The odds ratio assesses the relative risk of the target disorder occurring in the subjects presenting with a risk factor. The degree of significance of the odds ratio was estimated with a threshold of $\mathrm{p}<0.05$.

\section{Results}

\subsection{Our Sample}

198 subjects (7 men and 191 women) were enrolled in the study. 29 subjects (14.6\% of the population) were lost to follow-up as they were impossible to trace geographically. We obtained follow-up data for 115 (85.4\%) subjects:

- For various reasons, it was impossible to evaluate 25 (12.6\%) surviving subjects:

- 17 subjects (8.6\%) refused to participate in the study when they were first contacted by telephone.

- 8 subjects (4.1\%) never received our letter as their parents refused to forward it or provide us with their child's new address.

- 144 (72.7\%) subjects were evaluated:

- 3 subjects (1.5\%) had died. One young girl was killed as a passenger in a road accident and another girl with major cachexia, a sign of extremely severe anorexia nervosa, suffered cardiac arrest and died in the paediatric medical resuscitation room after all attempts to resuscitate her failed. A third girl committed suicide by defenestration one year after the end of treatment at the Nancy Children's Hospital.

- 69 subjects (34.8\%) answered the questionnaire only, without taking part in the clinical interview.

- 11 subjects (5.6\%) were evaluated by telephone interview and 58 (29.3\%) by direct interview during which answers to the questionnaires were obtained (except for one subject who was interviewed but felt that the self-evaluation questionnaires were too impersonal).

- 3 subjects (1.5\%) were evaluated by other means (one young girl chose to send a personal letter and additional information was obtained during a telephone interview with her father; other parents gave us news about their children either by mail or telephone).

Data for patients considered to be lost to follow-up were not analyzed in the same way as data for responders.

\subsection{Management at the Children's Hospital}

We obtained the clinical profiles and socio-demographic data of the 144 subjects included in our study from the medical notes taken at the time of their first admission to the Children's Hospital. The results are presented in Table 1. Table 2 shows the treatment received by these patients. Of the 144 subjects included, 97 were admitted to the unit at least once and 37 subjects were monitored as out-patients only.

\subsection{Clinical Profiles and Socio-Demographic Data at the Time of the Study}

The 144 subjects traced had an average age of slightly more than 22.5 years. A mean of 7 years (4 to 20 years) had elapsed since they were first admitted to the Children's Hospital. These subjects had a mean Body Mass Index (BMI) of 18.7, indicating that they had remained very slim. 13.2\% of the girls still presented with amenorea, 
Table 1. Clinical and socio-demographic characteristics on admission $(\mathrm{N}=144)$.

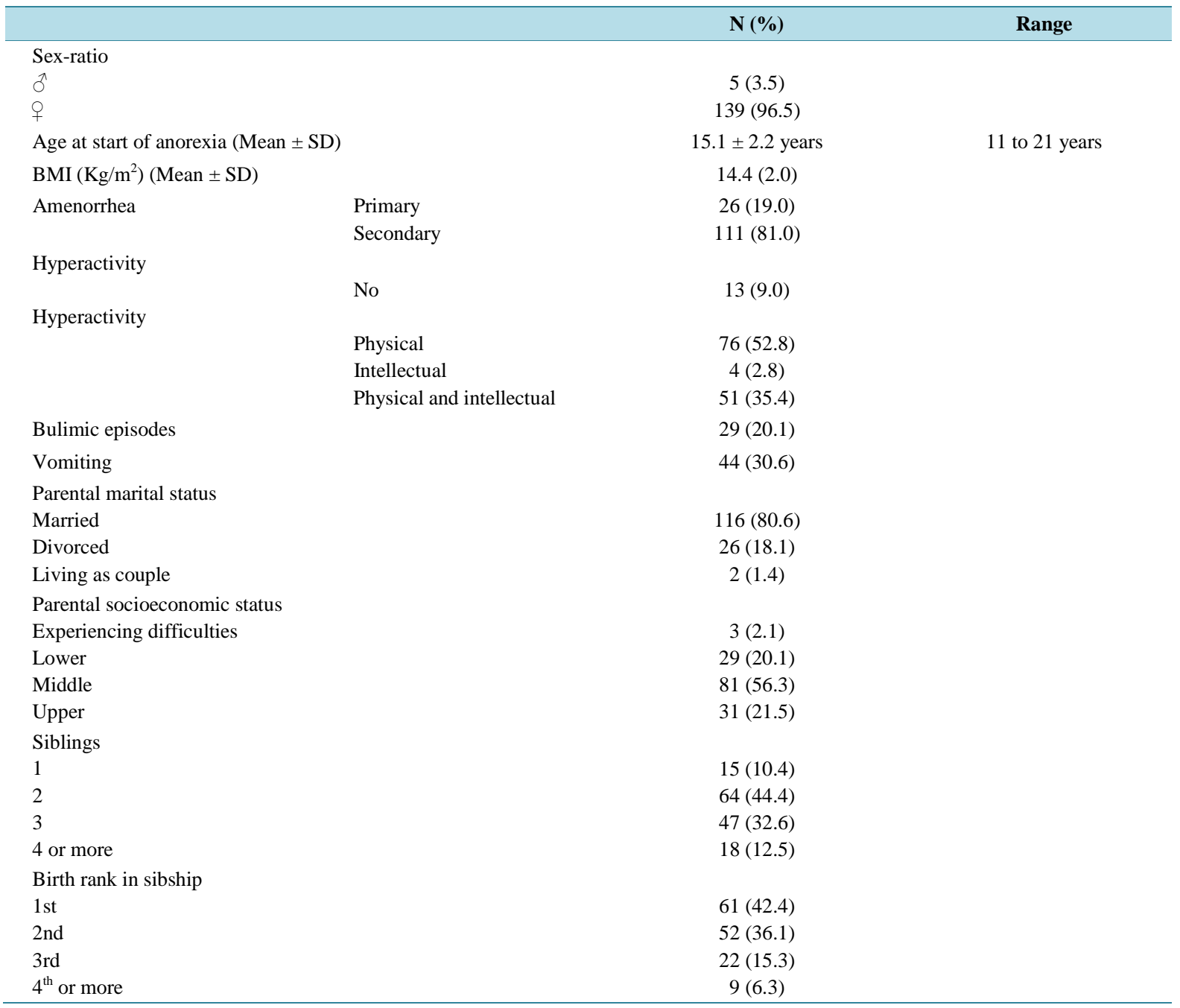

Mean \pm SD: mean \pm standard deviation.

Table 2. Initial treatment for anorexia nervosa $(\mathrm{N}=144)$.

\begin{tabular}{lcc}
\hline & N (\%) & Range \\
\hline Time from onset of symptoms to first treatment (months) (Mean \pm SD) & $11.5(9.4)$ \\
Number of hospitalizations per patient & $37(25.7)$ \\
0 & $66(61.7)$ \\
1 & $19(17.8)$ \\
2 & $12(11.2)$ \\
4 & $4(3.7)$ \\
5 or more & $6(4.6)$ \\
Mean number of hospitalizations per patient (Mean \pm SD) & $1.8(1.4)$ \\
Total duration of hospitalization Per patient (months) (Mean \pm SD) & $3(3.0)$ \\
CRNEF & $32(22.5)$ \\
Individual psychotherapy & $115(79.9)$ \\
Duration of treatment at Children's Hospital (months) (Mean \pm SD) & $21.3(20.4)$ \\
Family therapy & $18(12.5)$ \\
\hline
\end{tabular}

CRNEF: Constant rate nocturnal enteral feeding. Mean \pm SD: mean \pm standard deviation. 
but this figure should be interpreted with caution as $57 \%$ were taking oral contraceptives which could mask potentially persistent amenorrhea.

The clinical profiles and socio-demographic data of the subjects are shown in Table 3. The initial clinical and socio-demographic characteristics of the non responders did not differ.

\subsection{Overall Outcome at the Time of the Study}

The general self-evaluation questionnaire includes an item regarding current general health status. $40.7 \%$ of subjects considered their general health to be satisfactory, 37.9\% quite satisfactory and $21.4 \%$ unsatisfactory (Table 4). These results are inferior to those obtained from direct clinical assessment of the 69 subjects (68.1\% good outcome, $23.2 \%$ intermediate outcome and $8.7 \%$ poor outcome).

Using the LECE we found that $69.9 \%$ of the 69 subjects who were seen for clinical interview had a satisfactory diet. Generally speaking, outcome for personal relationships appeared positive, with satisfactory family relationships and friendships for $91.3 \%$ and $79.7 \%$ of subjects, respectively. Sexual relationships appeared satisfactory for $73.9 \%$ of subjects. Occupational activity (either studies or profession) was considered satisfactory for $87 \%$ of subjects.

The follow-up intervals between 4 and 20 years are very large. We therefore compared the outcomes of two sub-groups (less than 10 years, more than 10 years) and did not observe any statistically significant difference.

\subsection{Prognostic Factors}

Defining potential prognostic factors for the outcome of anorexia nervosa was a secondary objective of our study. The variables found to be statistically significant during the bivariate analysis were included in the logistic regression analysis, i.e. socioeconomic class of parents, individual past history of mental illness, prior treatment failure, age at first admission, duration of first symptoms, initial weight loss, duration of initial individual psychotherapy, rehospitalization and duration of psychotherapeutic monitoring in the intermediate period. Even if they were not significant during the bivariate analysis, variables considered to be predictive factors by other authors such as GOWERS and of interest to us, i.e. birth rank in sibship, BMI on admission and presence of vomiting or bulimic episodes, were also included [9].

Of the parameters studied, we were able to isolate 5 prognostic factors for positive outcome (Table 5):

Table 3. Clinical characteristics at the time of assessment at the time of study ( $\mathrm{N}=141)$.

\begin{tabular}{|c|c|c|c|}
\hline & & $\mathbf{N}(\%)$ & Range \\
\hline Age at inclusion (Mean \pm SD) & & $22.6 \pm 3.9$ years & 15 to 36 years \\
\hline Interval since start of anorexia (Mean \pm SD) & & $7 \pm 3.2$ years & 4 to 20 years \\
\hline Weight at assessment $(\mathrm{Kg})($ Mean \pm SD) & & $52.2(8,8)$ & \\
\hline BMI $\left(\mathrm{Kg} / \mathrm{m}^{2}(\right.$ Mean $\pm \mathrm{SD})$ & & $18.7(2.8)$ & \\
\hline Amenorrhea & & $18(13.2)$ & \\
\hline Oral contraceptives & & $77(57.0)$ & \\
\hline \multirow{3}{*}{ Family situation } & Single & $44(31.2)$ & \\
\hline & Living at home & $46(32.6)$ & \\
\hline & Married or living in a couple & $51(36.2)$ & \\
\hline \multirow{3}{*}{ Number of children } & None & $121(85.8)$ & \\
\hline & One & $16(11.4)$ & \\
\hline & Two & $4(2.8)$ & \\
\hline \multirow{4}{*}{ Socioprofessional category } & Not active & $16(11.4)$ & \\
\hline & Student & $81(57.9)$ & \\
\hline & Middle management, employee & $38(27.1)$ & \\
\hline & Upper management, self-employed & $5(3.6)$ & \\
\hline \multirow{3}{*}{ Family relationships } & Good & $90(63.8)$ & \\
\hline & Quite good & $43(30.5)$ & \\
\hline & Unsatisfactory & $8(5.7)$ & \\
\hline \multirow{3}{*}{ Friendships } & Good & $95(67.4)$ & \\
\hline & Quite good & $34(24.1)$ & \\
\hline & Unsatisfactory & $12(8.5)$ & \\
\hline
\end{tabular}

Mean \pm SD: mean \pm standard deviation. 
Table 4. Global scores on EAT-40, on HSCL, and LECE, overall self-assessment by patients and overall heteroevaluation by examiner.

\begin{tabular}{lccc}
\hline & Mean & SD & Range \\
\hline EAT-40 (N = 136) & 24.9 & 19.3 & $3-87$ \\
HSCL $(\mathbf{N}=\mathbf{1 3 6})$ & 42.2 & 31.0 & $0-131$ \\
LECE (interviews) $(\mathrm{N}=69)$ & 16.9 & 6.4 & 82 \\
Overall self-assessment by patients $(\mathrm{N}=141)$ & $\mathrm{N}(\%)$ & & \\
Satisfactory & $57(40.7)$ & & \\
Quite satisfactory & $53(37.9)$ & & \\
Unsatisfactory & $30(21.4)$ & $\mathrm{N}(\%)$ & \\
Overall hetero evaluation by examiner $(\mathrm{N}=69)$ & $47(68.1)$ & \\
Good outcome & $16(23.2)$ & \\
Intermediate outcome & $6(8.7)$ & \\
Poor outcome & & \\
\hline
\end{tabular}

EAT-40: Eating Attitudes Test. HSCL: Hopkins Symptom Check list. LECE: Examiner’s Clinical Assessment Chart. Mean \pm SD: mean \pm standard deviation.

Table 5. Prognostic factors: modelized probabilities.

\begin{tabular}{|c|c|c|c|}
\hline Modelized probability of an HSCL score $\geq 36(N=141)$ & OR & IC $95 \%$ & $\mathbf{p}$ \\
\hline No rehospitalisation & 0.23 & $0.09 ; 0.59$ & 0.002 \\
\hline No medical follow-up & 0.57 & $0.27 ; 1.21$ & 0.143 \\
\hline Duration of individual psychotherapy (>12 months) & 1.94 & $0.89 ; 4.22$ & 0.094 \\
\hline \multicolumn{4}{|l|}{ Modelized probability of an EAT-40 score $\geq 30(N=141)$} \\
\hline Parental SEC (3 versus 2) & 0.35 & $0.13 ; 0.89$ & 0.028 \\
\hline Parental SEC (4 versus 2) & 0.47 & $0.15 ; 1.49$ & 0.198 \\
\hline Duration of individual psychotherapy (>12 months) & 2.80 & $1.31 ; 6.30$ & 0.008 \\
\hline No rehospitalisation & 0.31 & $0.13 ; 0.74$ & 0.009 \\
\hline \multicolumn{4}{|c|}{$\begin{array}{l}\text { Modelized probability of global score }<8 \text { items scored "1" or “2” on LECE } \\
\text { ( }=69)\end{array}$} \\
\hline No medical follow-up & 0.39 & $0.12 ; 1.30$ & 0.12 \\
\hline No rehospitalisation & 0.26 & $0.07 ; 0.91$ & 0.03 \\
\hline Duration of individual psychotherapy (>12 months) & 5.01 & $1.46 ; 17.23$ & 0.01 \\
\hline \multicolumn{4}{|c|}{$\begin{array}{l}\text { Modelized probability of global score }<8 \text { items scored “1" or "2" on LECE } 7 \text { items } \\
(\mathrm{N}=141)^{*}\end{array}$} \\
\hline No prior treatment failure & 0.46 & $0.22 ; 0.97$ & 0.04 \\
\hline Duration of individual psychotherapy (>12 months) & 1.14 & $0.51 ; 2.55$ & 0.75 \\
\hline No rehospitalisation & 0.59 & $0.23 ; 1.48$ & 0.26 \\
\hline Duration of hospitalization ( $>1$ month) & 0.41 & $0.19 ; 0.88$ & 0.02 \\
\hline No medical follow-up & 1.08 & $0.50 ; 2.33$ & 0.84 \\
\hline
\end{tabular}

HSCL: Hopkins Symptom Check list. EAT-40: Eating Attitudes Test. LECE: Examiner’s Clinical Assessment Chart. SEC: Socioeconomic class. IC $95 \%$ is the $95 \%$ confidence interval of the odds ratio (OR). "ECAC 7 items: ECAC score established on basis of 7 items assessed in self-evaluation questionnaires, therefore other than the "mental status", "insight" and "addictive behaviour" items evaluated during clinical interview only.

- On admission

- Parents in middle socioeconomic class (as opposed to lower socioeconomic class);

- No prior treatment failure.

- During treatment at the Nancy Children's Hospital:

- Initial length hospitalization in excess of 1 month;

- Follow-up (hospitalisation(s) and/or monitoring appointments) $<12$ months.

- Finally, one parameter emerged from later follow-up data: 
- No rehospitalization.

\section{Discussion}

\subsection{Limits of Our Study}

- The lost to follow-up rate in our study is slightly higher than that recommended by HSU and is an indication of the difficulties inherent in collecting data from this patient group, and can be explained in several ways.

At the time of their first admission to hospital, these patients were adolescents living at home. In the interval between first treatment and our study many had left home and were thus more difficult to contact at the time of our study. There is no reason to think that the outcome of subjects who moved house would be any different from that of the subjects included in the study.

The long interval between the initial treatment for anorexia and our study did not always incite former patients to participate. We also encountered parents contacted by telephone who refused either to inform their child of our call or send on our letter. They were afraid that contact with us would bring back memories of difficult times or even cause a relapse.

- The subjects traced and included in our sample are still young (mean of 22.5 years, see Table 3). This is a limit to assessing their social adequacy. Many of them live alone or with their parents and are still students and only $14.2 \%$ have become parents themselves.

Would the results be different if this sample was re-assessed in a few years? Would these young adults have been able to found a family, flourish in their professional and social lives?

The youth of our patients is also a possible explanation for the low mortality rate we observed (3 deaths in the 144 subjects evaluated). However, it should be noted that 48 patients were lost to follow-up, some of whom may be deceased. According to the literature, the death by suicide rate rises over time. In the mean term (between 4 and 14 years after the initial episode), this rate ranges from $0 \%$ to $6 \%$. Measured over a longer monitoring period (20 to 35 years), this rate rises, reaching 17\% to 20\%. KEEL believes that suicide, and not the results of prolonged malnutrition, is the primary cause of death in anorexics [10]. The risk of death increases with age and mainly affects patients with the chronic forms of the disorder and those who are prone to relapse. In his study of 40 subjects, RATNASURYIA found an overall mortality rate of 5\% after 5 years and $17.5 \%$ after 20 years [11].

- Discrepancies were observed between the patient's self-evaluation and the interviewer's evaluation (Table 4). In addition to the fact that the sample size was not the same in the, this difference had already been made apparent in the study conducted by JEAMMET in which patients' assessment of their own overall status exceeded that of the interviewer [4]. The interviewer assesses mental status as an impersonal outsider and in addition, measures capacity for insight which is known to be defective in anorexic patients. JEAMMET believes that these differences are the result of psychological defence mechanism organization, leading to overestimation by subjects whose defence mechanisms have remained firmly in place or those who persistently continue to deny the actual existence of their disorder [4]. Conversely, the interviewer may under-estimate subjects who have relaxed their defences and are therefore able to express their suffering more openly.

\subsection{Contribution of Our Study}

With a homogeneous initial population of adolescents only, the outcome results observed in our sample can be considered to be reliable and can be compared to other studies following similar methodologies.

Our study confirmed the good outcome for patients with disease onset at adolescence [4] [12] (Table 6). More unusually, it showed a good outcome for patients even when the treatment proposed included a period of hospitalisation.

Our work also confirmed the non predominance of clear prognostic factors (GOWERS [9] [13], STEINHAUSEN [14]). However, our subsequent management of the disorder should be guided by the prognostic factors for positive outcome evidenced. We found 5 prognostic factors for positive outcome evidenced in our study.

At the time of admission, two factors emerged: these were "no prior treatment" and "parents in middle socioeconomic class (as opposed to lower class)".

Like many other regional university hospital centres, the Nancy Children's Hospital unit is used as a "last resort" after other treatment options have failed. Our recruitment methods therefore result in the selection of particularly difficult cases. Conversely, when we are called in to provide first line treatment (generally for cases 
Table 6. Comparison of overall outcomes found by 3 studies with similar methodologies.

\begin{tabular}{cccc}
\hline & $\begin{array}{c}\text { Our study } \\
(\mathrm{N}=144)\end{array}$ & $\begin{array}{c}\text { JEAMMET } \\
(\mathrm{N}=129)\end{array}$ & $\begin{array}{c}\text { WENTZ } \\
(\mathrm{N}=51)\end{array}$ \\
\hline Good outcome & $68.1 \%$ & $47 \%$ & $43 \%$ \\
Intermediate outcome & $23.2 \%$ & $38 \%$ & $29 \%$ \\
Poor outcome & $8.7 \%$ & $15 \%$ & $27 \%$ \\
\hline
\end{tabular}

living in the Nancy area), we treat adolescents with varying degrees of anorexia nervosa, hospitalization of the patient is not as frequently required and the prognosis is better.

We tried to work closely and intensively with parents before, during and after hospitalization. When a good therapeutic alliance with the parents is not possible, particularly with families experiencing socioeconomic difficulties, then the prognosis is not as good.

During the treatment period, 2 factors related to length of hospitalization appear influential: "stay of less than 1 month" or "in excess of one year".

These factors are supported by our findings in clinical practice: a patient leaving the unit "too soon” may have gained the requisite number of pounds for discharge, but not have addressed the psychological issues surrounding the disorder; in all likelihood, these patients will not have changed their behaviour patterns, even if their weight remains sufficiently high to not warrant readmission to the unit. Conversely, patients who remain too long in our unit tend to become static and difficult to mobilize. The unit and multidisciplinary team are often perceived as protection, a safe haven or barrier against an outside world seen as the enemy. The intrapsychic defence mechanisms of these patients are often incompletely developed and overly dependent on external realities.

Finally, the last good prognosis factor, i.e. "no rehospitalisation”, appears more obvious. We know by experience that patients who are unable to maintain an adequate minimum weight as soon as they are discharged from the unit, and who require frequent rehospitalization and display an extremely well defined set of symptoms and signs, are difficult to change and become too reliant on health care institutions. However, hope should never be lost for these patients and our best efforts should be directed towards assisting them on the road to an often long-awaited recovery.

In our experience hospitalisation, brief and not repeated, is often necessary.

Owing to practical and ethical difficulties, there are no randomised controlled trials of in-patient treatment in adolescent anorexia nervosa (GOWERS [9] [13], CRISP [15] [16]).

In 2001, LOCK declared: "the role of hospitalisation for anorexia nervosa has changed dramatically over the past 10 years, at least in the United States [17]. Currently, hospital treatment in the USA is limited to brief acute weight restoration and refeeding. However, low discharge weight appears to confer unnecessary risk for relapse and poor prognosis. Then inpatient treatment studies of young adults suggest a continued role for this modality of treatment for severe cases.

In 2000, GOWERS showed that the 21 adolescents who had received inpatient treatment had significantly worse outcome than the 51 never admitted to hospital [9]. The best fit model selected presence of in-patient admission first, followed by presenting MRGAS second. No others variables were selected as significant predictors of outcome once the two variables had been selected.

For these authors, although in-patient treatment is likely to be reserved for those with the most severe form of disorder, the results do not lend compelling support to the effectiveness of this intervention.

FICHTER describes the 12-year course of 103 anorexia nervosa patients who were all admitted to a Bavarian clinic for treatment [18]. The mortality was high and the symptomatic recovery was protracted. Impulsivity, symptom severity, and chronicity were the important factors for predicting the 12-year outcome. When their patients applied for the index treatment, they were almost 25 years old and exhibited a very chronic course of illness. This is different from the young anorexia nervosa patients treated in specialised child and adolescent psychiatry units who appear to have a better outcome than patients treated as adults.

Our results show that hospitalisation, if brief and not repeated, can be a positive prognosis factor. At Nancy, hospitalisation is considered necessary for patients who continue to lose weight or stabilise at a low bodyweight despite receiving outpatient treatment. Hospitalisation allows rapid weight gain and provides patients and their 
parents with new behaviour patterns to help maintain the weight gained and continue with the new dietary habits learned once they have left the unit.

\section{Conclusions}

Although the work carried out with anorexic adolescents over the past 20 years by the Nancy Children's Hospital is globally quite satisfactory, it should be borne in mind that our population was still relatively young at the time of the study and the number of subjects lost to follow-up was slightly high.

These results encourage us nevertheless to continue to use treatment methods based on the combined input of the paediatric and child psychiatry teams to care for adolescents who already evidently display the cardinal anorexic behaviour patterns and symptoms.

In this context, our working methods could be described as an integrative, multimodal and transtheoretical approach relying, as needed, on various combinations of inpatient and outpatient treatments and behavioural, psychodynamic and familial therapies.

When admitted to hospital at the appropriate point in the course of their disease, anorexic adolescents can learn new individual and familial behaviours which often prevent the disease from becoming chronic and allow the patient to go on to receive outpatient care under much improved conditions. Certainly, the financial burden of hospitalisation in a paedo-psychiatric unit is considerable but if it prevents chronic recurrence of the disease, it is a worthwhile investment leading, in the long term, to substantial savings in the costs involved in the prolonged care and repeated hospitalisation of young patients progressing towards chronic, severe anorexia.

\section{References}

[1] Steinhausen, H.C. (2002) The Outcome of Anorexia Nervosa in the 20th Century. American Journal of Psychiatry, 159, 1284-1293. http://dx.doi.org/10.1176/appi.ajp.159.8.1284

[2] Hsu, L.K. (1996) Epidemiology of the Eating Disorders. The Psychiatric Clinics of North America, 19, $681-700$. http://dx.doi.org/10.1016/S0193-953X(05)70375-0

[3] Van der Ham, T., Van Strien, D. and Van Engeland, H. (1994) A Four-Year Prospective Follow-Up Study of 49 Eating-Disordered Adolescents: Differences in Course of Illness. Acta Psychiatrica Scandinavica, 90, 229-235. http://dx.doi.org/10.1111/j.1600-0447.1994.tb01582.x

[4] Jeammet, P., Brechon, G., Payan, C., Gorge, A. and Fermanian, J. (1991) [The Outcome of Anorexia Nervosa: A Prospective Study of 129 Patients Evaluated at Least 4 Years after Their First Admission]. La Psychiatrie de l'Enfant, 34, 381-442.

[5] World Health Organisation (2001) Multiaxial Classification of Child and Adolescent Psychiatric Disorders. Masson, Paris.

[6] Guelfi, J.D., Barthelet, G., Lancrenon, S. and Fermanian, J. (1984) Factor Structure of the HSCL in a Sample of French Anxious-Depressed Patients. Annales Médico-Psychologiques, 142, 889-896.

[7] Garrot, G., Lang, F., Estour, B., Pellet, J., Gauthey, C. and Wagon, C. (1987) Study of the E. A. T., a Self-Evaluation Case in Anorexia in a Control Population and in a Sample of Anorectics. Annales Médico-Psychologiques (Paris), 145, 258-264.

[8] SAS Institute Inc. (1999) SAS: STAT User’s Guide, Release 8.2. SAS Institute Inc., Cary.

[9] Gowers, S.G., Weetman, J., Shore, A., Hossain, F. and Elvins, R. (2000) Impact of Hospitalisation on the Outcome of Adolescent Anorexia Nervosa. British Journal of Psychiatry, 176, 138-141. http://dx.doi.org/10.1192/bjp.176.2.138

[10] Keel, P.K., Dorer, D.J., Eddy, K.T., Franko, D., Charatan, D.L. and Herzog, D.B. (2003) Predictors of Mortality in Eating Disorders. Archives of General Psychiatry, 60, 179-183. http://dx.doi.org/10.1001/archpsyc.60.2.179

[11] Ratnasuriya, R.H., Eisler, I., Szmukler, G.I. and Russell, G.F. (1991) Anorexia Nervosa: Outcome and Prognostic Factors after 20 Years. British Journal of Psychiatry, 158, 495-502. http://dx.doi.org/10.1192/bjp.158.4.495

[12] Wentz, E., Gillberg, C., Gillberg, I.C. and Rastam, M. (2001) Ten-Year Follow-Up of Adolescent-Onset Anorexia Nervosa: Psychiatric Disorders and Overall Functioning Scales. Journal of Child Psychology and Psychiatry, 42, 613622. http://dx.doi.org/10.1111/1469-7610.00757

[13] Gowers, S.G., North, C.D., Byram, V. and Weaver, A.B. (1996) Life Event Precipitants of Adolescent Anorexia Nervosa. Journal of Child Psychology and Psychiatry, 37, 469-477. http://dx.doi.org/10.1111/j.1469-7610.1996.tb01428.x

[14] Steinhausen, H.C. and Glanville, K. (1983) A Long-Term Follow-Up of Adolescent Anorexia Nervosa. Acta Psychiatrica Scandinavica, 68, 1-10. http://dx.doi.org/10.1111/j.1600-0447.1983.tb06974.x 
[15] Crisp, A.H., Callender, J.S., Halek, C. and Hsu, L.K. (1992) Long-Term Mortality in Anorexia Nervosa. A 20-Year Follow-Up of the St George's and Aberdeen Cohorts. British Journal of Psychiatry, 161, 104-107. http://dx.doi.org/10.1192/bjp.161.1.104

[16] Crisp, A.H., Burns, T. and Bhat, A.V. (1986) Primary Anorexia Nervosa in the Male and Female: A Comparison of Clinical Features and Prognosis. British Journal of Psychiatry, 59, 123-132.

[17] Lock, J., Le Grange, D., Agras, W.S. and Dare, C. (2001) Treatment Manual for Anorexia Nervosav-A Family-Based Approach. The Guilford Press, New York.

[18] Fichter, M.M., Quadflieg, N. and Hedlung, S. (2006) Twelve-Year Course and Outcome Predictors of Anrexia Nervosa. International Journal of Eating Disorders, 39, 87-100. http://dx.doi.org/10.1002/eat.20215 
Scientific Research Publishing (SCIRP) is one of the largest Open Access journal publishers. It is currently publishing more than 200 open access, online, peer-reviewed journals covering a wide range of academic disciplines. SCIRP serves the worldwide academic communities and contributes to the progress and application of science with its publication.

Other selected journals from SCIRP are listed as below. Submit your manuscript to us via either submit@scirp.org or Online Submission Portal.
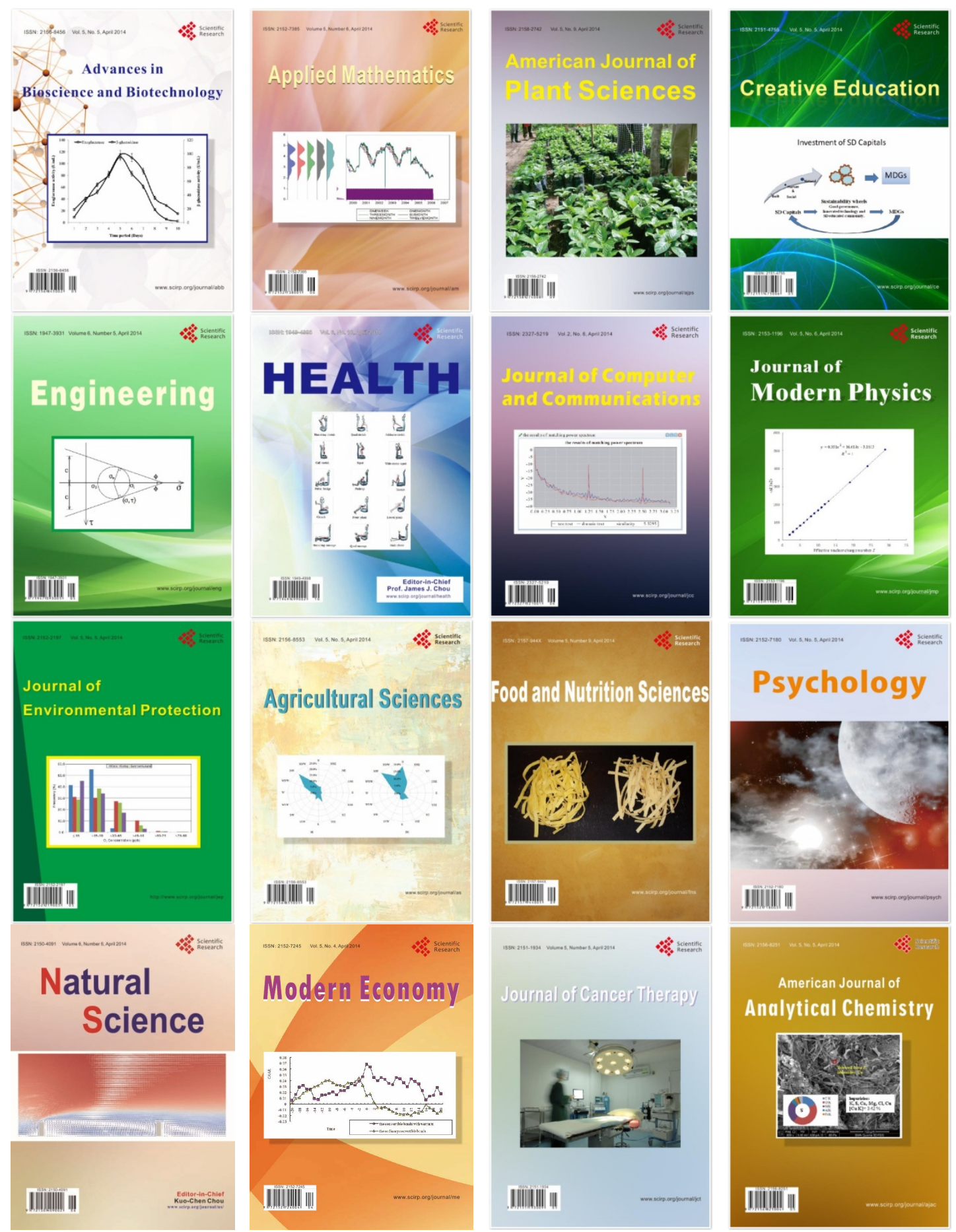